Article

\title{
Development of a New Ex Vivo Lipolysis-Absorption Model for Nanoemulsions
}

\author{
Lu Xiao ${ }^{1,+}$, Ying Liu ${ }^{2,+}$ and Tao Yi ${ }^{3, *}$ \\ 1 Department of Basic Medicine, Zunyi Medical University, Zhuhai Campus, Zhuhai 519041, China; \\ x11527@163.com \\ 2 Pharmacy Department, Wuhan Medical Treatment Center, Wuhan 430023, China; winter_ling@163.com \\ 3 School of Health Sciences, Macao Polytechnic Institute, Macau 999078, China \\ * Correspondence: yitao@ipm.edu.mo; Tel.: +853-85993471 \\ + These authors contributed equally to this work.
}

Received: 8 March 2019; Accepted: 29 March 2019; Published: 4 April 2019

check for updates

\begin{abstract}
The use of lipid-based formulations (LBFs) in improving the absorption of poorly water-soluble drugs has now well established. Because the in vivo evaluation of LBFs is labor-intensive, in vitro or ex vivo approaches could provide advantages. In this study, a new ex vivo lipolysis-absorption model (evLAM) composed of an intestinal digestion system and an intestinal tissue system was developed to evaluate and predict the in vivo absorption performances of LBFs. Model factors, including the $\mathrm{pH}$ of the system and concentrations of D-glucose and pancreatic lipase, were investigated and optimized by a Box-Behnken design. To evaluate this new model, a lipid formulation of indomethacin, which was chosen based on preliminary studies of pseudo-ternary phase diagrams, emulsion droplets, and solubility, was further investigated by an in vivo pharmacokinetic study of rats, the everted gut sac model, and the evLAM, respectively. The absorption percentages obtained from the evLAM were much more similar to the data of rats in vivo than those from the everted gut sac model, showing a preferable in vitro-in vivo correlation $(r=0.9772)$. Compared with the conventional in vitro and in vivo methods, the evLAM, which allowed precise insights into the in vivo absorption characteristics without much time or a complicated process, could be a better tool for assessing LBFs of poorly water-soluble drugs.
\end{abstract}

Keywords: lipid-based formulations; lipolysis; absorption; poorly water-soluble drugs; model

\section{Introduction}

For the oral delivery of poorly water-soluble drugs, lipid-based formulations (LBFs) have gained increasing attention due to enhanced oral bioavailability [1,2]. The main mechanism for the enhanced bioavailability of LBFs [3-8] was probably the pre-dissolved state of drugs in LBFs, which could reduce the energy associated with the solid-to-liquid phase transition process and cause the enhanced drug solubilization by colloidal structures. The formations of colloidal structures were the results of interactions among LBFs, their digestion products, and endogenous surfactants such as bile salts and phospholipids [9-13]. The powerful digestive system in the intestine could play an important role in the fate of LBFs [14,15].

It is very important to provide a fast and accurate method to evaluate the in vitro and in vivo characteristics of LBFs. Because the in vivo pharmacokinetics study is expensive and labor-intensive, the evaluation of LBFs by in vitro or ex vivo assays could present important advantages. Conventional in vitro methods for screening formulation and evaluating characteristics of LBFs are based on the pseudo-ternary phase diagram, the comparison of droplet size and solubility, and the in vitro lipolysis [16,17]. Phase diagram, emulsion droplet size, and in vitro solubility assays are 
important for the preliminary choice of a lipid-based formulation, especially for microemulsions and self-microemulsifying drug delivery systems. However, the in vitro findings in these assays only correlate poorly with the in vivo absorption characteristics.

The in vitro lipolysis model for assessing the fate of drugs of LBFs, whether they were soluble or precipitated in the intestinal digestive system, has been well-recognized [18-24]. The standard in vitro lipolysis assay was performed using a $\mathrm{pH}$-stat to maintain the $\mathrm{pH}$ of the system, adding porcine pancreatin to serve as a lipase-colipase model for human pancreatic juice, and using bile salt-lecithin mixed micelles to provide a solubilization environment. The data generated from the $\mathrm{pH}$-stat could be used to quantify the rate and extent of lipolysis through recording the amounts of free fatty acids released from LBFs. After the reaction had been terminated, the products of lipolysis could be examined to determine the fate of the drug after lipolysis $[5,19]$. The in vitro lipolysis model is useful for the optimization of LBFs and has been used for lipid nanoparticles [25]. Since the pancreatic extract contained both the pancreatic lipase and carboxyl ester hydrolase, the in vitro lipolysis model was improved by using porcine pancreatic extract, as it was therefore permitted to mimic the duodenal digestive lipolysis in a biorelevant manner. However, the in vitro lipolysis model may not be predictive for actual in vivo absorptions due to the lack of effective simulation of the internal physiological environment. However, the in vitro lipolysis model may not be predictive for actual in vivo absorptions due to the lack of effective simulation of the internal physiological environment [24].

The everted gut sac model (EGSM), commonly using intact intestinal mucosal epithelium of rats to mimic the in vivo conditions, has been widely used to pharmacokinetic studies such as drug absorption, drug metabolism in intestinal segments, efflux transport, multidrug resistance, and drug interactions [26]. The viability of intestinal segments under in vitro conditions was impacted by experimental factors such as $\mathrm{pH}$, aeration, temperature, and the concentration of the substance. The EGSM provides a relatively large surface area available for absorption and a mucus layer. Consequently, results from EGSM have been in agreement with in vivo findings for many drugs [26]. However, the EGSM could not accurately evaluate LBFs due to the lack of the simulation of the lipolytic condition. Therefore, it was hypothesized that the combination of the EGSM and the in vitro lipolysis model could form a new ex vivo model which should be much closer to the in vivo conditions and, resultantly, could evaluate LBFs more accurately.

The first aim of this study was to establish a new ex vivo lipolysis-absorption model (evLAM) for evaluating and predicting the in vivo performance of LBFs. In this study, the evLAM composed of an intestinal digestion system (a pH-stat to maintain the $\mathrm{pH}$ of the system, adding porcine pancreatin to serve as a lipase-colipase model for human pancreatic juice, and using bile salt-lecithin mixed micelles to provide a solubilization environment) and an intestinal tissue system (intestinal segments under physiological medium to obtain absorption data). The new evLAM was much closer to the in vivo conditions and resultantly could evaluate LBFs more accurately. Model factors, including the $\mathrm{pH}$ of the system and concentrations of $\mathrm{Ca}^{2+}$, D-glucose, $\mathrm{K}^{+}$, and pancreatic lipase, were investigated and optimized by a three-level Box-Behnken design. The $\mathrm{pH}$ of the system, concentrations of D-glucose, and pancreatic lipase were chosen as the independent variables; the intestinal tissue activity and the fatty acid concentration were the dependent variables $[19,27,28]$.

Furthermore, the in vitro absorptions obtained from the new evLAM and the conventional EGSM were compared with the pharmacokinetics data of rats. The in vitro-in vivo correlations of absorption curves obtained from the two models were further compared to indicate the advantages of the new model in evaluating and predicting the in vivo performance of LBFs.

\section{Experimental Section}

\subsection{Materials}

Sodium taurodeoxycholate $(97 \%)$, porcine pancreatin $(8 \times$ USP specifications activity), and Trizma maleate $(99.5 \%)$ were purchased from Sigma Chemical Co. (St. Louis, MO, USA). Medium chain mono- 
and di-glyceride (Capmul MCM) were kindly donated by Abitec Co. (Janesville, WI, USA). Lecithin (approximately 80\% pure phosphatidylcholine) was a gift from Q.P. Co. (Fuchu-Shi, Tokyo, Japan). Indomethacin (99.5\%) was purchased from Zizhu Pharmaceutical Co. (Beijing, China). The Naproxen sodium reference substance $(99.9 \%)$ and indomethacin reference substance $(99.9 \%)$ were purchased from the China Institute for the Control of Drugs and Biological Products (Beijing, China). A lactate dehydrogenase Assay Kit was purchased from the Nanjing Jiancheng Bioengineering Institute (Nanjing, China). Other chemicals were of HPLC or analytical grade.

\subsection{Preparation of the Intestinal Tissue Medium in the Fasted State}

$1.25 \mathrm{mM}$ of lecithin was dissolved in chloroform in a round bottom flask, and then chloroform was evaporated off under vacuum, resulting in a thin film of lecithin around the bottom of the flask. After the addition of $5 \mathrm{mM}$ of sodium taurodeoxycholate, $50 \mathrm{mM}$ of Trizma maleate, and $150 \mathrm{mM}$ of $\mathrm{NaCl}$ and $\mathrm{Ca}^{2+}$ solution (at 1, 3, 5 or $10 \mathrm{mM}$ ), the mixed solution was adjusted with $\mathrm{NaOH}$ or $\mathrm{HCl}$ to a $\mathrm{pH}$ of $7.500 \pm 0.001$ and then stirred and equilibrated for $12 \mathrm{~h}$; after which, it finally formed a clear and slightly yellow solution. At last, D-glucose solution (at $0,5,10$ or $15 \mathrm{mM}$ ) and $\mathrm{K}^{+}$solution $($at $0,3.5,5.5$ or $6.5 \mathrm{mM}$ ) were added in before use.

\subsection{Preparation of Intestinal Segments}

All surgical and experimental procedures were approved by the Animal Research Ethics Committee of Zunyi Medical University (No.: ZMCER2018A051). Male Wistar rats (Chongqing, China) 11-12 weeks old, $250 \pm 20 \mathrm{~g}$ in weight, and fasted for $24 \mathrm{~h}$ prior to the experiment were anaesthetized intraperitoneally with $3.5 \%$ chloral hydrate $\left(1 \mathrm{~mL} \cdot 100 \mathrm{~g}^{-1}\right)$. The small intestine was removed out and washed three times with saline $\left(0.9 \% \mathrm{NaCl}\right.$ solution) at $37^{\circ} \mathrm{C}$. The intestine was immediately placed in an oxygenated $\left(\mathrm{O}_{2}: \mathrm{CO}_{2}=95: 5 \% v / v\right)$ intestinal tissue medium $\left(\mathrm{pH} 7.5,37^{\circ} \mathrm{C}\right)$. The intestinal segment ( $5-7 \mathrm{~cm}$ in length) was everted on a tube $(2.5 \mathrm{~cm}$ in diameter), and then one end was sealed with a clamp.

\subsection{Establishment of the evLAM}

A new evLAM, composed of an intestinal tissue system (intestinal segment, medium, temperature controlled stirrer, vents, and $\mathrm{O}_{2} / \mathrm{CO}_{2}$ ) and an intestinal digestion system (pH-stat meter controller, $\mathrm{NaOH}$ autoburette, $\mathrm{pH}$ electrodes, and computer) was set up based on characteristics of intestinal digestion of LBFs. As shown in Figure 1, the intestinal segment was filled with fresh and oxygenated intestinal tissue medium using a $1 \mathrm{~mL}$ glass syringe and then incubated in a centrifuge tube containing oxygenated intestinal tissue medium with the lipid-based formulation to be assayed at $37^{\circ} \mathrm{C}$. Lipase and pancreatin were used to mimic the intestinal digestive lipolysis in a biorelevant manner. Then, the pancreatic lipase extract, which was prepared by adding $1 \mathrm{~g}$ of porcine pancreatic lipase powder into $5 \mathrm{~mL}$ of digestion buffer (Trizma maleate, $\mathrm{NaCl}, \mathrm{Ca}^{2+}, \mathrm{pH} 7.5$ ) and stirred for $15 \mathrm{~min}$ followed by centrifugation at $1,600 \times \mathrm{g}$ and $5{ }^{\circ} \mathrm{C}$ for $15 \mathrm{~min}$, was added to initiate lipolysis. In the process of the lipolysis, the $\mathrm{pH}$ of the system was sustained by a $\mathrm{pH}$-stat automatic titration unit with $0.2 \mathrm{M}$ $\mathrm{NaOH}$. At designated intervals of $2 \mathrm{~h}$ experiment, samples of $200 \mu \mathrm{L}$ were collected from the gut sac and conserved at $-20^{\circ} \mathrm{C}$ until analysis. Each experiment was performed by three parallel treatments, and the average value was used. At the same time, the fresh intestinal tissue medium with the same volume was added. 


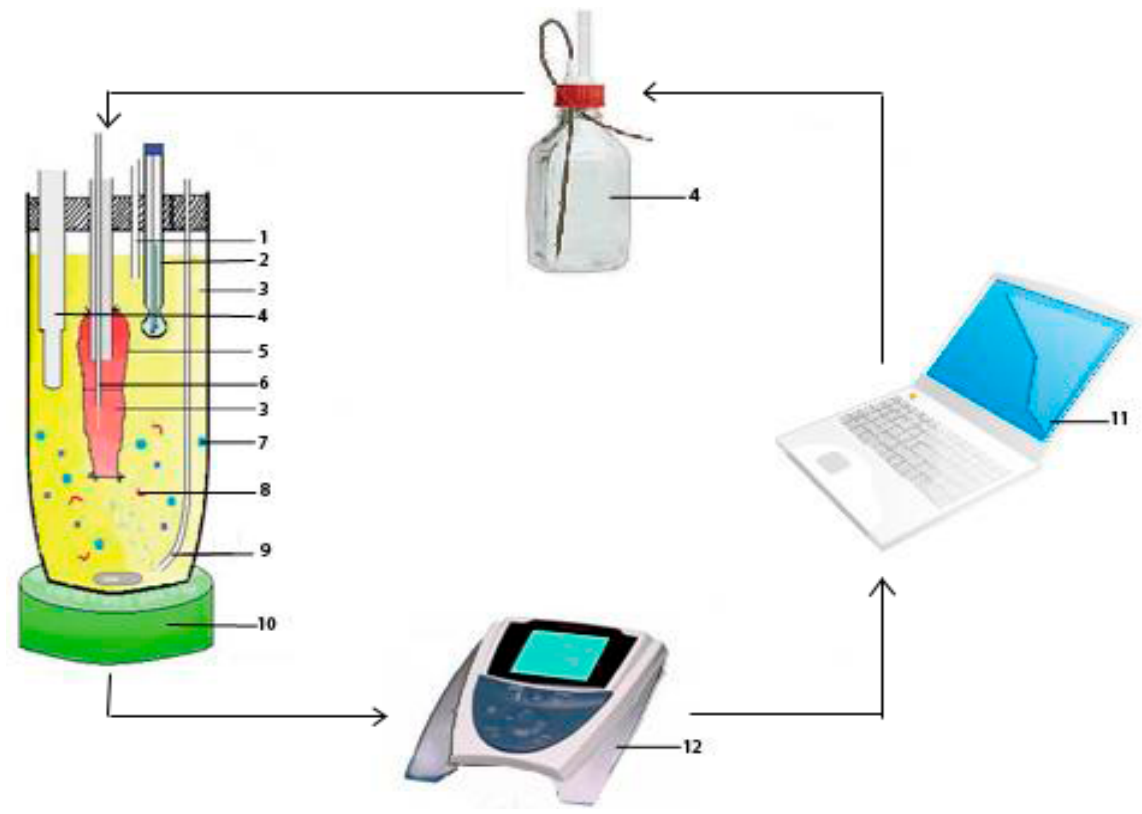

Figure 1. The new lipolysis-absorption model for lipid-based formulations: (1) Vent; (2) $\mathrm{pH}$ electrode; (3) intestinal tissue medium; (4) $\mathrm{NaOH}$ autoburette; (5) intestinal segment; (6) sampler; (7) a lipid-based formulation; (8) pancreatic lipase/colipase; (9) $\mathrm{O}_{2} / \mathrm{CO}_{2} ;(10)$ temperature controlled stirrer; (11) computer; and (12) pH-stat meter controller.

\subsection{Optimization of the evLAM}

\subsubsection{Measurement of the Attenuation Rate of Intestinal Tissue Activity}

The concentrations of lactate dehydrogenase in the sample at every time point was measured by the lactate dehydrogenase assay kit. The determination was performed three times, and the average value was used. The attenuation rate (AR) of intestinal tissue activity was calculated as follows.

$$
\mathrm{AR}=\left(\mathrm{CLDH}_{\text {end }}-\mathrm{CLDH}_{0}\right) / \text { time interval }
$$

where $\mathrm{CLDH}_{\text {end }}$ was the concentration of lactate dehydrogenase at the end, and $\mathrm{CLDH}_{0}$ was the concentration of lactate dehydrogenase at the beginning. The release of lactate dehydrogenase increased with the increasing damage of intestinal tissue. The faster intestinal tissue activity decreased, the faster the attenuation rate was.

\subsubsection{Analysis of the Amount of Fatty Acids}

The release of free fatty acids from the lipolysis of LBFs was monitored using a titration method [29]. The amount of fatty acids in each sample was determined by the end-point titration with $0.2 \mathrm{M}$ of $\mathrm{NaOH}$. The determination was performed by three parallel treatments, and the average value was used.

\subsubsection{Three-Level Box-Behnken Design}

A three-level Box-Behnken design comprised of 15 experimental runs was constructed by Design-Expert (Version 8.0.0, Stat-Ease Inc., Minneapolis, MN, USA) [30]. Independent variables and dependent variables are listed in Table 1 along with their low, medium, and high levels and target value, which were selected based on results from preliminary experiment. 
Table 1. Variables and their levels in the Box-Behnken design.

\begin{tabular}{|c|c|c|c|}
\hline \multirow{2}{*}{ Factor } & \multicolumn{3}{|c|}{ Levels used, Actual (Coded) } \\
\hline & Low $(-1)$ & Medium (0) & High (+1) \\
\hline \multicolumn{4}{|c|}{ Independent variables } \\
\hline$X_{1}=$ the $\mathrm{pH}$ of the system & 6.5 & 7.5 & 8.5 \\
\hline$X_{2}=$ D-glucose concentration $(\mathrm{mM})$ & 5 & 10 & 15 \\
\hline$X_{3}=$ pancreatic lipase concentration $\left(\right.$ unit $\left.\cdot \mathrm{mL}^{-1}\right)$ & 2500 & 4250 & 6000 \\
\hline Dependent variables & \multirow{3}{*}{\multicolumn{3}{|c|}{$\begin{array}{l}\text { Target value } \\
\text { Minimize } \\
4.468 \sim 4.703\end{array}$}} \\
\hline$Y_{1}=$ Attenuation rate of intestinal tissue activity $\left(\mathrm{U} \cdot \mathrm{L}^{-1} \cdot \mathrm{min}^{-1}\right)$ & & & \\
\hline$Y_{2}=$ Amount of Fatty Acids (mmol) & & & \\
\hline
\end{tabular}

\subsection{Evaluation of the evLAM}

\subsubsection{Choosing a Lipid-Based Formulation of Indomethacin}

A lipid formulation of indomethacin was chosen as follows: Solubility and pseudo-ternary phase diagrams were first studied to obtain four formulations, Formulation I to IV (shown in Supplementary Figures S1 and S2). Then, in vitro characteristics of these four formulations, such as the droplet size, self-emulsifying efficiency, and solubility, were determined (shown in Supplementary Table S1). Based on the results, the optimal formulation of indomethacin, Formulation II composed of Labrafac@Lipohile WL1349, Cremophor RH40, and Transcutol P (20:60:20, w/w), was chosen for further studies. The solubility of indomethacin in Formulation II was $32.19 \mathrm{mg} / \mathrm{g}$, and the drug content of indomethacin in Formulation II was $16.0 \mathrm{mg} / \mathrm{g}$. After lipolysis, the proportion of drug dispersed in aqueous phase and precipitation phase was $86.95 \pm 0.75 \%$ and $12.50 \pm 0.26 \%$, respectively.

\subsubsection{HPLC Analysis of Indomethacin}

The concentration of indomethacin was determined by an HPLC analysis system (Agilent 1200, Agilent Technologies, Santa Clara, CA, USA) with an Agilent ODS-C18 column $(250 \times 4.6 \mathrm{~mm}$, $5 \mu \mathrm{m})$. The column temperature was $25^{\circ} \mathrm{C}$, and the injection volume was $10 \mu \mathrm{L}$. The mobile phase was a mixture of acetonitrile and $0.1 \mathrm{M}$ sodium acetate at a ratio of 40:60 $(v / v)$, with $\mathrm{pH}$ of 5.0 adjusted by acetic acid. The detection was carried out at a wavelength of $320 \mathrm{~nm}$, with a flow rate of $1.0 \mathrm{~mL} / \mathrm{min}$. The percent relative standard deviation (RSD\%) of method precision was lower than $2 \%$. The observed-to-expected ratios for spiking recovery ranged from $100.8 \%$ to $101.1 \%$, showing the acceptable accuracy of the method. The sensitivity of the method represented by limit of quantitation was $0.1 \mu \mathrm{g} / \mathrm{mL}$.

\subsubsection{Comparison of the In Vitro Absorption between evLAM and EGSM}

The evLAM optimized above was used to investigate the in vitro intestinal absorption of indomethacin of Formulation II. Briefly, a known quantity of Formulation II ( $250 \mathrm{mg}$ formulation per $10 \mathrm{~mL}$ intestinal tissue medium) was crudely emulsified in the intestinal tissue medium in a centrifuge tube. Lipolysis was initiated by the addition of pancreatic lipase extract into the gut sac. Samples were collected at designated intervals, and drug concentrations were measured by HPLC as described above. The in vitro cumulative absorption percentage $\left(P_{a}\right)$ was calculated as follows:

$$
P_{a}=\frac{\left(V_{\text {mea }} \times C_{\mathrm{n}} \times \frac{V_{\text {bal }}}{V_{\text {sam }}}+V_{\text {mea }} \times \sum_{t=1}^{n-1} C_{\mathrm{i}}\right) / V}{C} \times 100 \%
$$

where $C_{\mathrm{n}}$ was the drug concentration of each sample; $V_{\text {bal }}$ was the volume of the intestinal tissue medium before balance; $V_{\text {sam }}$ was the volume of samples collected at each time point; $V_{\text {mea }}$ was the volume of samples measured at each time point; $V$ was the total volume of the intestinal tissue medium in the gut sac; and $C$ was the initial drug concentration. 
The conventional EGSM was also used to study the in vitro intestinal absorption of indomethacin of Formulation II. After anesthesia of rats, an intestinal segment (about $6 \mathrm{~cm}$ ) was removed rapidly. The segment was washed with saline at $4{ }^{\circ} \mathrm{C}$ and everted over a glass rod gently. One end of the everted segment was tied with suture, and then the intestinal segment was filled with Krebs solution at $37^{\circ} \mathrm{C}$ by needle tubing. The other end of the filled intestinal segment was hanged up with a tie. Finally, the intestinal segment was put into a beaker containing $20 \mathrm{~mL}$ medium with Formulation II at $37^{\circ} \mathrm{C}$. Samples of $0.1 \mathrm{~mL}$ were collected at designated intervals, and the drug concentrations were measured by HPLC as described above. The blank medium of $0.1 \mathrm{~mL}$ was replenished at each time point. The value of $P_{a}$ was also calculated as described above.

\subsubsection{In Vivo Absorption Study of Indomethacin LBF}

A pharmacokinetic study was designed to investigate the in vivo absorption of the indomethacin LBF, Formulation II. Five Male Wistar rats $(250 \pm 10 \mathrm{~g})$, which had been acclimatized for at least 1-2 weeks before the experiment, were fasted for $24 \mathrm{~h}$ prior to drug administration but allowed free access to water. Formulation II was administered intragastrically to each rat at a dose of $4.5 \mathrm{mg} \cdot \mathrm{kg}^{-1}$ of indomethacin. About $200 \mu \mathrm{L}$ of blood sample was collected from the rat tail vein into heparinized tubes at designated time intervals [31]. Plasma was separated by centrifugation and stored at $-20^{\circ} \mathrm{C}$ until analysis.

The concentration of indomethacin in plasma was determined by HPLC [32] as follows: $10 \mu \mathrm{L}$ of internal standard solution (200 mg. $\mathrm{L}^{-1}$ naproxen sodium solution) was added into $150 \mu \mathrm{L}$ of plasma and mixed for $5 \mathrm{~min}$. Then, $15 \mu \mathrm{L}$ of a phosphate buffer (pH 7.0) and $20 \mathrm{mg}$ of $\mathrm{NaCl}$ were added. The sample was extracted with $375 \mu \mathrm{L}$ acetidin by vortex-mixing for $10 \mathrm{~min}$ and centrifuging at $10,000 \times g$. The supernatant was transferred to a clean tube and evaporated by nitrogen purging. The residue was reconstituted in $50 \mu \mathrm{L}$ methanol. After vortex-mixing for $10 \mathrm{~min}, 20 \mu \mathrm{L}$ of the sample was used for HPLC as described above. The 3p97 computer program and a Wagner-Nelson method were employed to analyze the plasma concentration-time data. The in vivo absorption percentage $\left(f_{\mathrm{a}}\right)$ was calculate as follows.

$$
f_{a}=\frac{C_{\mathrm{t}}+K_{\mathrm{e}} \int_{0}^{\tau} C_{\mathrm{t}} \mathrm{d} t}{K_{\mathrm{e}} \int_{0}^{\infty} C_{\mathrm{t}} \mathrm{d} t} \times 100 \%
$$

where $C_{\mathrm{n}}$ was the drug concentration at each time point, and $K_{\mathrm{e}}$ was the elimination rate constant.

\subsection{Statistical Analysis}

All data were expressed as mean $\pm \mathrm{SD}$. Statistical analysis and data fitting were performed using SPSS 16.0 (SPSS Inc., Chicago, IL, USA). One-way analysis of variance (ANOVA) was performed to test differences for statistical significance. Difference between mean values was considered statistically significant at $p<0.05$ and very statistically significant at $p<0.001$.

\section{Results and Discussion}

\subsection{Effects of Components of the evLAM on Activity of Intestinal Tissue}

As a new model for assessing the in vitro absorption of LBFs, it was important to simulate the actual dynamics of intestinal fluids. Because the viability of intestinal tissue under in vitro conditions was impacted by many factors, it was also important to select components of this new evLAM based on the minimal tissue damage. Components of the evLAM and their concentration ranges were all chosen as a compromise between in vivo values as the literatures reported [27,28,33-37] and pre-experiments in our laboratory. Trizma maleate was chosen at the concentration of $50 \mathrm{mM}$, which was similar to that used in other studies [19,38-42]. Sodium taurodeoxycholate and phosphatidylcholine were both added because that the administered exogenous lipids and their digestion products could intercalate into endogenous sodium taurodeoxycholate and phosphatidylcholine structures, changing the nature of solubilizing species, promoting micelle swelling and further increasing solubilization 
capacity $[10,15,33]$. Concentrations of sodium taurodeoxycholate and phosphatidylcholine in intestinal fluid after oral administration of LBFs have not been reported, so $5 \mathrm{mM}$ of sodium taurodeoxycholate and $1.25 \mathrm{mM}$ phosphatidylcholine were chosen in the evLAM based on their typical concentrations in the fasted state as the literatures reported $[10,15,33]$.

Influences of $\mathrm{Ca}^{2+}$, D-glucose, $\mathrm{K}^{+}, \mathrm{pH}$, and pancreatic lipase on the activity of intestinal segments in the evLAM were investigated. Value ranges of these model factors were set up based on the literatures. The same amount of Formulation II was used in the evLAM with different levels of model factors. Attenuation rates of the activity of intestinal segments under different conditions were measured and are shown in Figure 2.

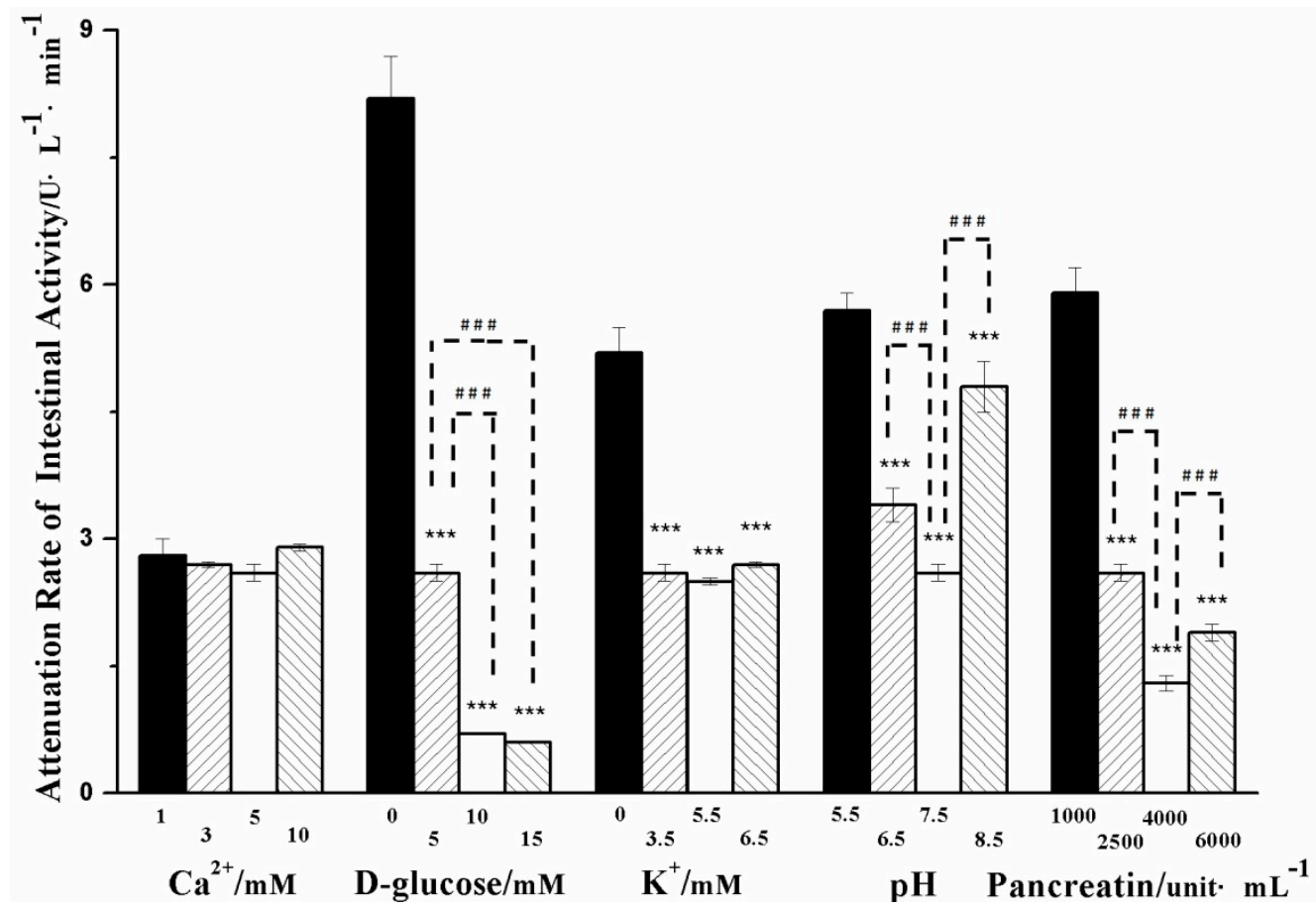

Figure 2. Influences of $\mathrm{Ca}^{2+}, \mathrm{D}$-glucose, $\mathrm{K}^{+}, \mathrm{pH}$, and pancreatic lipase on the attenuation rate of the intestinal tissue activity of the ex vivo lipolysis-absorption model. (Mean \pm S.D., $n=5$ ). ${ }^{* * *}$ very statistically significant $(p<0.001)$ compared with D-glucose of $0 \mathrm{mM}, \mathrm{K}^{+}$of $0 \mathrm{mM}$, pancreatic lipase of 1000 uint $\cdot \mathrm{mL}^{-1}$ and $\mathrm{pH}$ of 5.5 , respectively. ${ }^{\# \#}$ very statistically significant $(p<0.001)$ difference in pairwise comparison.

Though there was no mention of a calcium binding site in the 3-D structure of pancreatic lipase/co-lipase complex [34,35], $\mathrm{Ca}^{2+}$ was necessary for the activity of pancreatic lipase. The formation of $\mathrm{Ca}^{2+}$-soaps could draw the equilibrium towards the ionized fatty acids and maintain lipolysis in the presence of bile [36]. The mean concentration of $\mathrm{Ca}^{2+}$ in the fasted state was $0.5-3 \mathrm{mM}$ in the duodenum, and $\mathrm{Ca}^{2+}$ of 1-10 mM was investigated in the previous studies [27,28,37]. As shown in Figure 2, no significant differences in the attenuation rate of intestinal tissue activity were seen in a range of $\mathrm{Ca}^{2+}$ concentrations, which suggested that $\mathrm{Ca}^{2+}$ did not directly influence the activity of intestinal tissue.

The attenuation rate of intestinal tissue activity decreased with the increasing concentration of D-glucose in the range of 0-15 mM, suggesting that the higher concentration of D-glucose could maintain the activity of intestinal tissue for a much longer time. It was probably due to that D-glucose was the energy source for cell metabolism.

The attenuation rate of intestinal tissue activity was significantly decreased after adding $\mathrm{K}^{+}$. This could be due to the fact that the $\mathrm{Na}^{+}$pump was usually activated upon $\mathrm{K}^{+}$, benefitting the secondary active transport of D-glucose [43] and providing more energy to intestinal tissue cells. However, when 
the amount of $\mathrm{K}^{+}$was sufficient in the concentration range of 3.5-6.5 mM, there were no significant changes in attenuation rate of intestinal tissue activity.

The $\mathrm{pH}$ value of the in vitro lipolysis model showed a high variability ranging from 5.8 to $8.5[27,28]$. As shown in Figure 2, the decreased attenuation rate of intestinal tissue activity appeared significantly at the $\mathrm{pH}$ range of 5.5 to 7.5 , but the increased attenuation rate of intestinal activity was observed at $\mathrm{pH}$ 8.5. It was suggested that it was important for the activity of intestinal tissue to select a moderate $\mathrm{pH}$.

The pancreatic lipase had an activity of $500-600$ unit. $\mathrm{mL}^{-1}$ in the fasted state and 800-1800 unit $\cdot \mathrm{mL}^{-1}$ in the fed state, respectively $[14,34,35]$. In some previous studies, the pancreatic lipase reached up to $10,000 \mathrm{unit} \cdot \mathrm{mL}^{-1}$ [19]. As shown in Figure 2, the attenuation rate of intestinal tissue activity was significantly decreased when the pancreatic lipase concentration increased from 1000 to 4000 unit $\mathrm{mL}^{-1}$, but the attenuation rate increased when the pancreatic lipase reached up to 6000 unit $\cdot \mathrm{mL}^{-1}$. It was suggested that excessive pancreatic lipase might damage intestinal tissue.

From the results above, it could be seen that the $\mathrm{pH}$ of the system, concentrations of D-glucose, and pancreatic lipase had much more influence on the activity of intestinal tissue than the other model factors. Therefore, these three factors were chosen as independent variables of Box-Behnken design for optimizing the evLAM.

\subsection{Optimization of the evLAM by Box-Behnken Design}

All the responses observed for 15 experimental runs were simultaneously fitted to first order, second order, and quadratic models by Design Expert 8.0. It was observed that the best-fitted model was the quadratic model. Comparative values are given in Table 2 along with the regression equations generated for each response. Only statistically significant $(p<0.05)$ coefficients were included in the equations.

A positive value indicated an effect that favored the optimization, while a negative value represented an inverse relationship between the factor and the response. As shown in Table 2, it was evident that the $\mathrm{pH}$ of the system $\left(X_{1}\right)$ had positive effects on the two responses-the attenuation rate of intestinal tissue activity $\left(Y_{1}\right)$ and the amount of fatty acids $\left(Y_{2}\right)$. Concentrations of D-glucose $\left(X_{2}\right)$ and pancreatic lipase $\left(X_{3}\right)$ had positive effects on the amount of fatty acids but had negative effects on the attenuation rate of intestinal tissue activity. More than one factor term or the coefficients with higher order terms in the regression equation represented, respectively, interaction terms or quadratic relationships, which suggests that the relationships between factors and responses were not always linear. As shown in Table 2, the interaction effect of concentrations of D-glucose and pancreatic lipase was only positive for the attenuation rate of intestinal tissue activity, but interaction effects between $\mathrm{pH}$ and D-glucose concentration, $\mathrm{pH}$, and pancreatic lipase concentration were unfavorable for the amount of fatty acids. Higher and positive quadratic effects of $\mathrm{pH}$ and D-glucose concentration were observed for both the attenuation rate of intestinal tissue activity and the amount of fatty acids. Quadratic effects of pancreatic lipase concentration were positive or negative for the attenuation rate of intestinal tissue activity and the amount of fatty acids, respectively.

Table 2. Regression analysis for responses for fitting to quadratic model.

\begin{tabular}{|c|c|c|c|c|c|}
\hline & $R^{2}$ & Adjusted $R^{2}$ & Predicted $R^{2}$ & SD & $\% \mathrm{CV}$ \\
\hline$Y_{1}$ & 0.9999 & 0.9996 & 0.9982 & 0.026 & 1.31 \\
\hline$Y_{2}$ & 0.9966 & 0.9921 & 0.9656 & 0.16 & 3.32 \\
\hline \multicolumn{6}{|c|}{ Regression equations of the fitted quadratic model } \\
\hline \multicolumn{6}{|c|}{$Y_{1}=0.40+0.69 X_{1}-0.99 X_{2}-0.40 X_{3}-0.08 X_{1} X_{2}-0.049 X_{1} X_{3}+0.064 X_{2} X_{3}+1.33 X_{1}^{2}+0.74 X_{2}^{2}+0.82 X_{3}^{2}$} \\
\hline \multicolumn{6}{|c|}{$Y_{2}=4.55+2.13 X_{1}+0.27 X_{2}+0.75 X_{3}-0.089 X_{1} X_{2}-0.20 X_{1} X_{3}+0.72 X_{1}^{2}+0.10 X_{2}^{2}-0.41 X_{3}^{2}$} \\
\hline
\end{tabular}


Three-dimensional response surface plots, which could represent interactions of all factors on the responses more clearly, are shown in Figures 3 and 4. When the third factor was kept at a constant level, these plots were very useful in study of the effects of another two factors on the response at the same time.

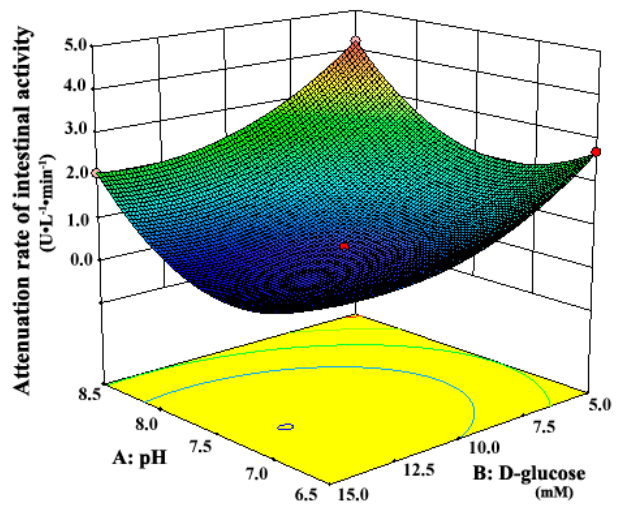

(a)

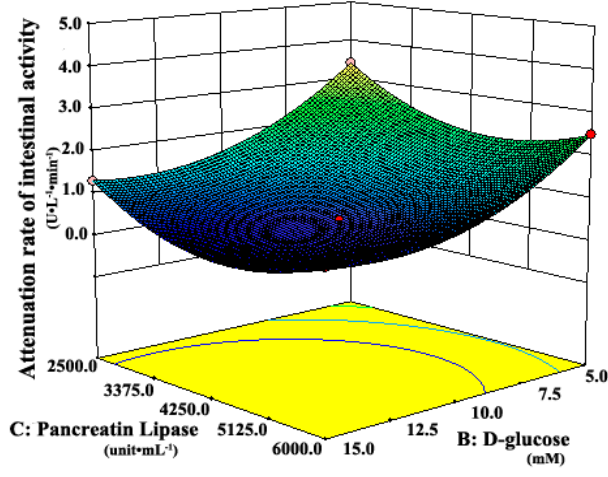

(c)

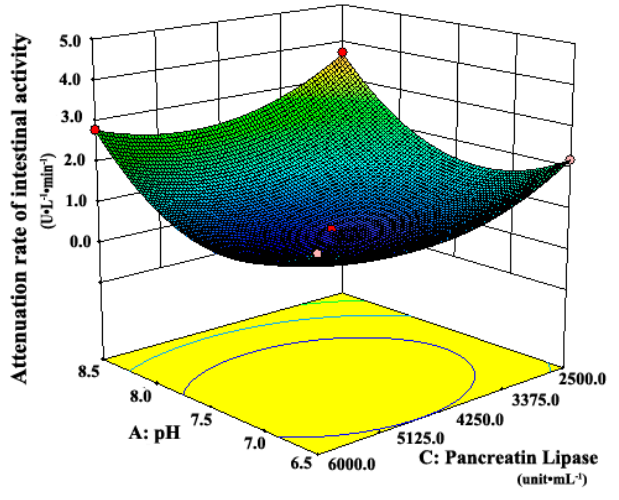

(b)

Figure 3. Response surface plots showing interaction effects of $\mathrm{pH}$, D-glucose, and pancreatic lipase on the attenuation rate of intestinal tissue activity when (a) pancreatic lipase, (b) D-glucose, and (c) $\mathrm{pH}$ held constant, respectively.

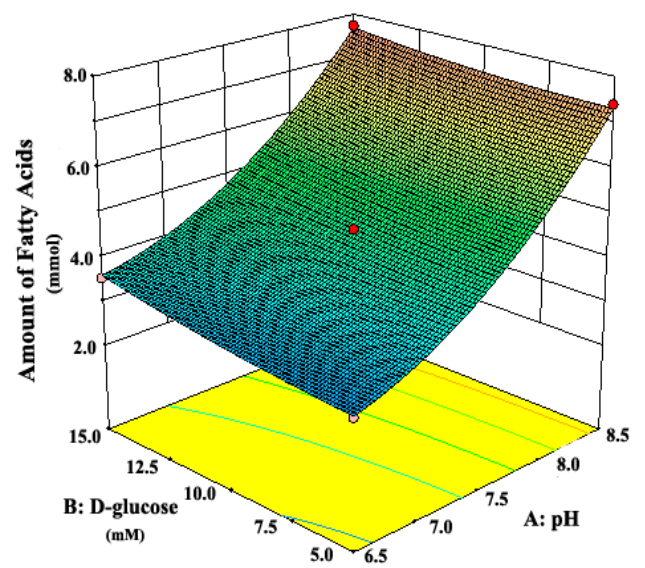

(a)

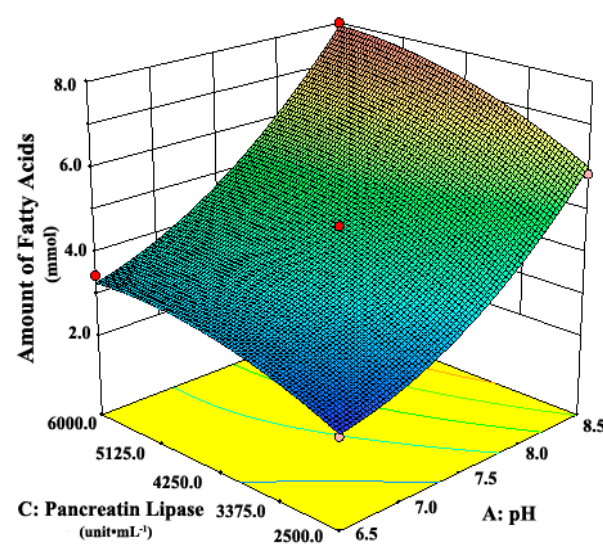

(b)

Figure 4. Response surface plots showing interaction effects of $\mathrm{pH}$, D-glucose, and pancreatic lipase on the amount of fatty acids from digestion when (a) pancreatic lipase or (b) D-glucose held constant, respectively. 
As shown in Figure 3a, when the $\mathrm{pH}$ of the system was 6.5 or 8.5 , the attenuation rates of intestinal tissue activity were higher than those at other moderate levels of $\mathrm{pH}$, regardless of the D-glucose concentration. A similar observation can be seen in Figure 3b. The attenuation rate of intestinal tissue activity increased when the $\mathrm{pH}$ of the system changed from the middle to the both ends of the range of 6.5 to 8.5 , whether at low or high concentration of pancreatic lipase. It suggested that the moderate $\mathrm{pH}$ was favorable for the intestinal tissue activity, which was due to that the moderate $\mathrm{pH}$ simulated the physiological environment of intestinal tract in vivo. However, Figure 4 shows that the amount of fatty acids increased always with the increasing $\mathrm{pH}$, which suggests that the high $\mathrm{pH}$ could promote the in vitro lipolysis. It might be due to that pancreatic lipase showed the highest catalytic activity in vitro around $\mathrm{pH}$ of 8 [35,40-42]. In the literature [28,35,40-42], the $\mathrm{pH}$ was usually set about 7.4, which was the optimum value for the intestinal cell culture and the best activity of pancreas lipase.

Figure 3a shows that the attenuation rate of intestinal tissue activity decreased as D-glucose concentration increased from $5.0 \mathrm{mM}$ to $15.0 \mathrm{mM}$, whether at low or high level of $\mathrm{pH}$. A similar observation can be seen in Figure 3c. The attenuation rate of intestinal tissue activity decreased with the increasing concentration of D-glucose, whether at low or high concentration of pancreatic lipase. The possible explanation was that more energy source from D-glucose was provided for intestinal tissue cells at higher concentrations of D-glucose, which could maintain the activity of intestinal tissues well in vitro. Moreover, Figure 4 a shows that there was a slight increase in the amount of fatty acids with the increase of D-glucose concentration, whether at low or high level of $\mathrm{pH}$. All the results above suggested that the high concentration of D-glucose was favorable for the evLAM.

As shown in Figure 3b, the attenuation rate of intestinal tissue activity would be at the least level when the concentration of pancreatic lipase was in the middle of the range of 2500 to $6000 \mathrm{unit} \cdot \mathrm{mL}^{-1}$, whatever the $\mathrm{pH}$ of the system was. Figure $3 \mathrm{c}$ shows the similar variation trends in the attenuation rate of intestinal tissue activity with the concentration of pancreatic lipase, whether at low or high concentration of D-glucose. However, Figure $4 \mathrm{~b}$ shows that the amount of fatty acids increased with the increasing concentration of pancreatic lipase, which suggested that the high concentration of pancreatic lipase could promote the in vitro lipolysis. Thus, the optimal concentration of pancreatic lipase should be a compromise between the optimal conditions in vitro for the intestinal tissue activity and the lipolysis.

The optimum evLAM was selected based on the criteria for attaining the optimum value of the model by applying constraints on the attenuation rate of intestinal tissue activity (minimum) and the amount of fatty acids (4.468 $\left.\leq Y_{2} \leq 4.703\right)$. Based on 'trading of' various response variables and comprehensive evaluation of feasibility search and exhaustive grid search, the evLAM with $\mathrm{pH}$ of 7.37, D-glucose of $12.06 \mathrm{mM}$, and pancreatic lipase of $4.94 \times 10^{3} \mathrm{unit} \cdot \mathrm{mL}^{-1}$ was found to fulfill the optimum model. The predicted values and the observed values were in reasonably good agreement (Table 3 ).

Table 3. Optimized values obtained by the constraints applied on the attenuation rate of intestinal tissue activity $\left(Y_{1}\right)$ and the amount of fatty acids $\left(Y_{2}\right)$ (Mean \pm S.D., $\left.n=5\right)$.

\begin{tabular}{ccccc}
\hline Variable & Nominal Values & Response & Predicted Values & Observed Values \\
\hline$X_{1}$ (the $\mathrm{pH}$ of the system) & 7.37 & $Y_{1}\left(\mathrm{U} \cdot \mathrm{L}^{-1} \cdot \mathrm{min}^{-1}\right)$ & 0.041 & $0.047 \pm 0.002$ \\
$X_{2}$ (D-glucose concentration) & $12.06(\mathrm{mM})$ & $Y_{2}(\mathrm{mmol})$ & 4.629 & $4.355 \pm 0.720$ \\
$X_{3}$ (pancreatic lipase & $4.94 \times 10^{3}\left(\right.$ unit $\left.\cdot \mathrm{mL}^{-1}\right)$ & & & \\
concentration) & & & & \\
\hline
\end{tabular}

\subsection{Evaluate of the evLAM by the Pharmacokinetics in Rats}

The first aim of this study was to establish the ex vivo lipolysis-absorption model for evaluating and predicting the in vivo performance of LBFs. We conducted the in vivo pharmacokinetic studies to obtain the real absorption of formulations in vivo. Figure 5 shows that absorption percentages obtained from the new evLAM $\left(P_{\mathrm{a} 1}\right)$ were far higher than those from the conventional EGSM $\left(P_{\mathrm{a} 2}\right)$ within $2 \mathrm{~h}$. The EGSM provided a relatively large surface area available for absorption and a mucus layer [26] but lacked the simulation of lipolytic condition, resulting in the inadequate absorption 
in vitro of LBFs. On the contrary, the evLAM provided the almost real environment for the digestion of LBFs. Therefore, the in vitro absorption of poorly water-soluble drugs in LBFs could be obtained more accurately by the evLAM.

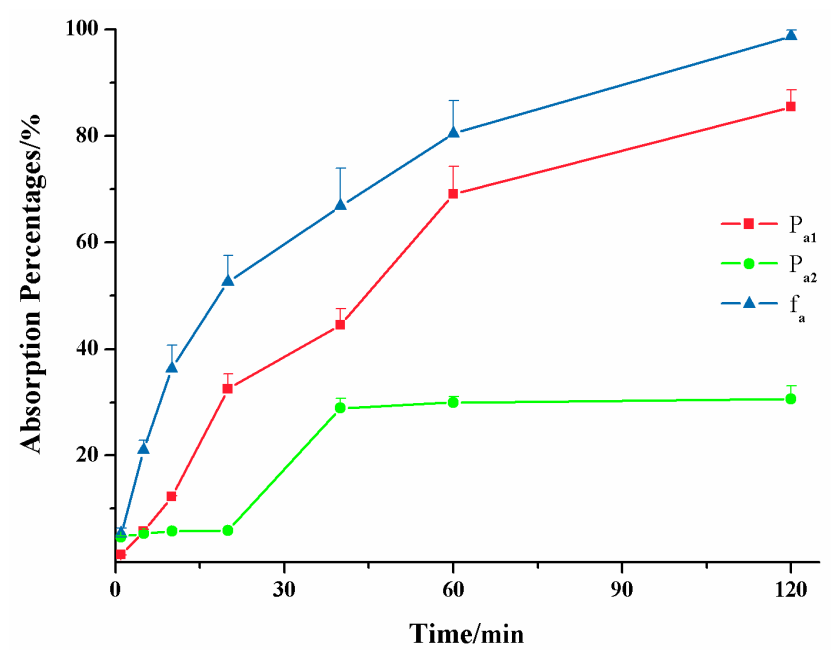

Figure 5. Absorption percentages of the lipid-based formulation of indomethacin from the new ex vivo lipolysis-absorption model $\left(\square, P_{\mathrm{a} 1}\right)$, the conventional everted gut sac model $\left(\bullet, P_{\mathrm{a} 2}\right)$ and pharmacokinetics test of rats $\left(\Delta, f_{\mathrm{a}}\right)$ within $2 \mathrm{~h}$. $(n=5)$.

Figure 6 shows the in vitro-in vivo correlations (IVIVC) of absorption curve obtained from the new evLAM and the conventional EGSM. The regression correlation coefficient $(r)$ of IVIVC for the $\operatorname{evLAM}\left(r_{1}=0.9773, n=7\right)$ was far higher than the critical correlation coefficient $(r=0.8740, P<0.01$, $n=7)$, while $r$ for the EGSM $\left(r_{2}=0.7852, n=7\right)$ was below the critical correlation coefficient. Therefore, there was a significant correlation between the absorption curve from the evLAM and the in vivo absorption curve of rats. It was suggested that the evLAM possessed good ability to predict the in vivo performance of lipid formulations. On the contrary, there was no significant correlation between the absorption curve from the EGSM and the in vivo absorption curve of rats. Indeed, these results demonstrated that the evLAM, allowed precise insights into the in vivo absorption characteristics of LBFs, which suggests that it should be an attractive and great potential method for screening formulation and evaluating characteristics of LBFs.

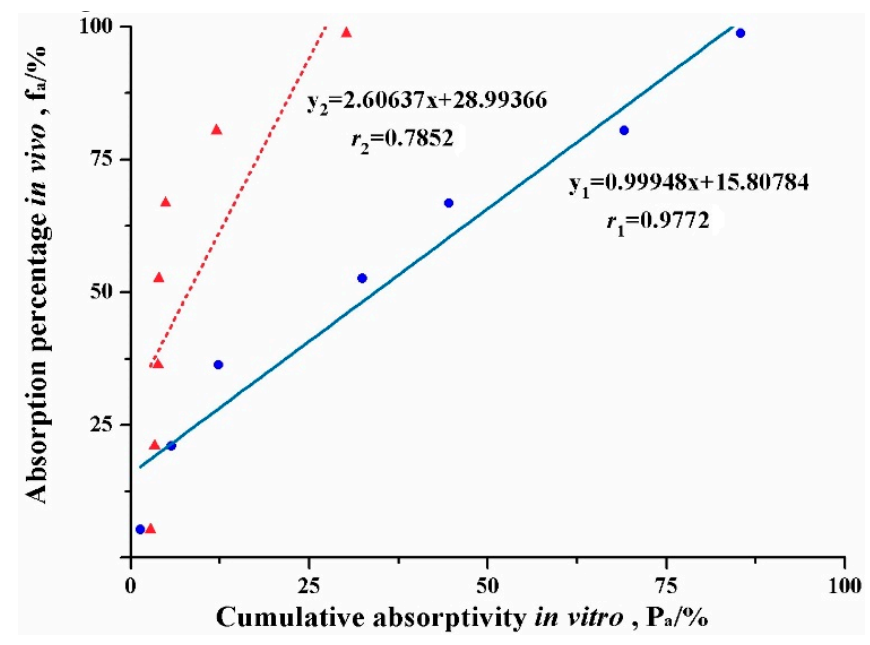

Figure 6. Plots of the in vivo-in vitro correlation of absorption curve for the lipid-based formulation of indomethacin obtained from the conventional everted gut sac model $(\boldsymbol{\Delta})$ and the new ex vivo lipolysis-absorption model $(\bullet)$, respectively. 


\section{Conclusions}

In this paper, a new evLAM was developed to predict the intestinal absorptions of poorly water-soluble drugs in LBFs. This new model was composed of an intestinal digestion system and an intestinal tissue system. D-glucose, pancreatic lipase, and $\mathrm{pH}$ significantly affected the in vitro activity of intestinal tissue and the in vitro lipolysis. The optimal model parameters by the Box-Behnken design were set up as follows: a $\mathrm{pH}$ of 7.37, D-glucose of $12.06 \mathrm{mM}$, and a pancreatic lipase of $4.94 \times 10^{3}$ unit. $\mathrm{mL}^{-1}$. For a typical lipid-based formulation, absorption percentages obtained from the optimal evLAM showed a much better IVIVC with absorption percentages of rats in vivo. The new evLAM could make up for the inadequacy of conventional methods and be a better tool for assessing LBFs of poorly water-soluble drugs.

Supplementary Materials: The following are available online at http:/ / www.mdpi.com/1999-4923/11/4/164/s1, Figure S1. Pseudo-ternary Phase Diagrams: "Me" represented microemulsion area; (A) the mixing ratio of Cremophor RH40 and Transcutol P was 3:1; (B) the mixing ratio of Cremophor RH40 and Transcutol P was 1:1; (C) the mixing ratio of Cremophor RH40 and Transcutol P was 1:3. Figure S2. The microscopic images of the four formulations. Formulations were showed as labeled and the ruler was in the bottom right corner of the diagram. Table S1. Self-emulsifying Time, droplet Size, appearance and solubility of indomethacin for the nanoemulsions (mean, $n=5$ ).

Author Contributions: All authors contributed to this work. T.Y. designed and conducted the study. Y.L. performed the experiments. L.X analyzed the data and prepared the original draft. T.Y. revised the manuscript and also supervised this work.

Funding: This research was funded by the Doctoral Starting up Foundation of Zunyi Medical University (F-880), Open Fund Project of Key laboratory of Basic Pharmacology of Ministry of Education (KY[2018]484), the Science and Technology Development Fund of Macao Special Administrative Region (001/2016/A1), the Macao Polytechnic Institute Research Fund (RP/ESS-01/2018), the Research Fund for Wuhan Municipal Health and Family Planning (WX18Q42), and Zhuhai Premier-Discipline Enhancement Scheme of Pharmacology, Zhuhai Campus of Zunyi Medical University.

Conflicts of Interest: The authors declare no conflict of interest.

\section{References}

1. Esfanjani, A.F.; Assadpour, E.; Jafari, S.M. Improving the bioavailability of phenolic compounds by loading them within lipid-based nanocarriers. Trends Food Sci. Technol. 2018, 76, 56-66. [CrossRef]

2. Jafari, S.M.; Mcclements, D.J. Nanotechnology Approaches for Increasing Nutrient Bioavailability. Adv. Food Nutr. Res. 2017, 81, 1-30.

3. Zeng, N.; Gao, X.; Hu, Q.; Song, Q.; Xia, H.; Liu, Z.; Gu, G.; Jiang, M.; Pang, Z.; Chen, H.; et al. Lipid-based liquid crystalline nanoparticles as oral drug delivery vehicles for poorly water-soluble drugs: Cellular interaction and in vivo absorption. Int. J. Nanomed. 2012, 7, 3703-3718.

4. Wasan, K.M. Formulation and physiological and biopharmaceutical issues in the development of oral lipid-based drug delivery systems. Drug Dev. Ind. Pharm. 2001, 27, 267-276. [CrossRef]

5. Pouton, C.W. Formulation of poorly water-soluble drugs for oral administration: Physicochemical and physiological issues and the lipid formulation classification system. Eur. J. Pharm. Sci. 2006, 29, 278-287. [CrossRef]

6. Pouton, C.W.; Porter, C.J. Formulation of lipid-based delivery systems for oral administration: Materials, methods and strategies. Adv. Drug Deliv. Rev. 2008, 60, 625-637. [CrossRef]

7. Porter, C.J.H.; Pouton, C.W.; Cuine, J.F.; Charman, W.N. Enhancing intestinal drug solubilisation using lipid-based delivery systems. Adv. Drug Deliv. Rev. 2008, 60, 673-691. [CrossRef]

8. Trevaskis, N.L.; Charman, W.N.; Porter, C.J. Lipid-based delivery systems and intestinal lymphatic drug transport: A mechanistic update. Adv. Drug Deliv. Rev. 2008, 60, 702-716. [CrossRef]

9. Hur, S.J.; Joo, S.T.; Lim, B.O.; Decker, E.A.; McClements, J.D. Impact of salt and lipid type on in vitro digestion of emulsified lipids. Food Chem. 2011, 126, 1559-1564. [CrossRef] [PubMed]

10. Kossena, G.A.; Boyd, B.J.; Porter, C.J.H.; Charman, W.N. Separation and characterization of the colloidal phases produced on digestion of common formulation lipids and assessment of their impact on the apparent solubility of selected poorly water-soluble drugs. J. Pharm. Sci. 2003, 92, 634-648. [CrossRef] 
11. Kossena, G.A.; Charman, W.N.; Boyd, B.J.; Porter, C.I.H. Influence of the intermediate digestion phases of common formulation lipids on the absorption of a poorly water-soluble drug. J. Pharm. Sci. 2005, 94, 481-492. [CrossRef]

12. Kossena, G.A.; Charman, W.N.; Boyd, B.J.; Dunstan, D.E.; Porter, C.J. Probing drug solubilization patterns in the gastrointestinal tract after administration of lipid-based delivery systems: A phase diagram approach. J. Pharm. Sci. 2004, 93, 332-348. [CrossRef]

13. Wiedmann, T.S.; Kamel, L. Examination of the solubilization of drugs by bile salt micelles. J. Pharm. Sci. 2002, 91, 1743-1764. [CrossRef]

14. Armand, M.; Borel, P.; Pasquier, B.; Dubois, C.; Senft, M.; Andre, M.; Peyrot, J.; Salducci, J.; Lairon, D. Physicochemical characteristics of emulsions during fat digestion in human stomach and duodenum. Am. J. Physiol. 1996, 271 (Pt 1), G172-G183. [CrossRef]

15. Hernell, O.; Staggers, J.E.; Carey, M.C. Physical-chemical behavior of dietary and biliary lipids during intestinal digestion and absorption. 2. Phase analysis and aggregation states of luminal lipids during duodenal fat digestion in healthy adult human beings. Biochemistry 1990, 29, 2041-2056. [CrossRef]

16. Kim, H.J.; Yoon, K.A.; Hahn, M.; Park, E.S.; Chi, S.C. Preparation and in vitro evaluation of self-microemulsifying drug delivery systems containing idebenone. Drug Dev. Ind. Pharm. 2000, 26, 523-529. [CrossRef]

17. Cirri, M.; Mura, P.; Mora, P.C. Liquid spray formulations of xibornol by using self-microemulsifying drug delivery systems. Int. J. Pharm. 2007, 340, 84-91. [CrossRef]

18. Dai, W.G. In vitro methods to assess drug precipitation. Int. J. Pharm. 2010, 393, 1-16. [CrossRef]

19. Sek, L.; Porter, C.J.H.; Charman, W.N. Characterisation and quantification of medium chain and long chain triglycerides and their in vitro digestion products, by HPTLC coupled with in situ densitometric analysis. J. Pharm. Biomed. 2001, 25, 651-661. [CrossRef]

20. Brogard, M.; Troedsson, E.; Thuresson, K.; Ljusberg-Wahren, H. A new standardized lipolysis approach for characterization of emulsions and dispersions. J. Colloid Interface Sci. 2007, 308, 500-507. [CrossRef]

21. Zangenberg, N.H.; Mullertz, A.; Kristensen, H.G.; Hovgaard, L. A dynamic in vitro lipolysis model. I. Controlling the rate of lipolysis by continuous addition of calcium. Eur. J. Pharm. Sci. 2001, 14, 115-122. [CrossRef]

22. Han, S.F.; Yao, T.T.; Zhang, X.X.; Gan, L.; Zhu, C.; Yu, H.Z.; Gan, Y. Lipid-based formulations to enhance oral bioavailability of the poorly water-soluble drug anethol trithione: Effects of lipid composition and formulation. Int. J. Pharm. 2009, 379, 18-24. [CrossRef] [PubMed]

23. Li, Y.; Hu, M.; McClements, D.J. Factors affecting lipase digestibility of emulsified lipids using an in vitro digestion model: Proposal for a standardised pH-stat method. Food Chem. 2011, 126, 498-505. [CrossRef]

24. Dahan, A.H.A. Use of a dynamic in vitro lipolysis model to rationalize oral formulation development for poor water soluble drugs: Correlation with in vivo data and the relationship to intra-enterocyte processes in rats. Pharm. Res. 2006, 23, 2165-2174. [CrossRef] [PubMed]

25. Jannin, V.; Dellera, E.; Chevrier, S.; Chavant, Y.; Voutsinas, C.; Bonferoni, C.; Demarne, F. In vitro lipolysis tests on lipid nanoparticles: Comparison between lipase/co-lipase and pancreatic extract. Drug Dev. Ind. Pharm. 2015, 41, 1582-1588. [CrossRef] [PubMed]

26. Alam, M.A.; Al-Jenoobi, F.I.; Al-Mohizea, A.M. Everted gut sac model as a tool in pharmaceutical research: Limitations and applications. J. Pharm. Pharmacol. 2012, 64, 326-336. [CrossRef] [PubMed]

27. Alvarez, F.J.; Stella, V.J. The role of calcium ions and bile salts on the pancreatic lipase-catalyzed hydrolysis of triglyceride emulsions stabilized with lecithin. Pharm. Res. 1989, 6, 449-457. [CrossRef]

28. Hu, M.; Li, Y.; Decker, E.A.; McClements, D.J. Role of calcium and calcium-binding agents on the lipase digestibility of emulsified lipids using an in vitro digestion model. Food Hydrocoll. 2010, 24, 719-725. [CrossRef]

29. Mun, S.; Decker, E.A.; Park, Y.; Weiss, J.; McClements, D.J. Influence of interfacial composition on in vitro digestibility of emulsified lipids: Potential mechanism for chitosan's ability to inhibit fat digestion. Food Biophys. 2006, 1, 21-29. [CrossRef]

30. Williams, H.D.; Sassene, P.; Kleberg, K.; Bakala-N'Goma, J.C.; Calderone, M.; Jannin, V.; Igonin, A.; Partheil, A.; Marchaud, D.; Jule, E.; et al. Toward the establishment of standardized in vitro tests for lipid-based formulations, part 1: Method parameterization and comparison of in vitro digestion profiles across a range of representative formulations. J. Pharm. Sci. 2012, 101, 3360-3380. [CrossRef] 
31. Zhou, J.; Zhu, F.; Li, J.; Wang, J. Concealed body mesoporous silica nanoparticles for orally delivering indometacin with chiral recognition function. Mater. Sci. Eng. C 2018, 90, 314-324. [CrossRef] [PubMed]

32. Al Za'abi, M.A.; Dehghanzadeh, G.H.; Norris, R.L.; Charles, B.G. A rapid and sensitive microscale HPLC method for the determination of indomethacin in plasma of premature neonates with patent ductus arteriousus. J. Chromatog. B Anal. Technol. Biomed. Life Sci. 2006, 830, 364-367. [CrossRef] [PubMed]

33. Ali, H.N.M.; Zaghloul, A.A.; Nazzal, S. Comparison between lipolysis and compendial dissolution as alternative techniques for the in vitro characterization of alpha-tocopherol self-emulsified drug delivery systems (SEDDS). Int. J. Pharm. 2008, 352, 104-114. [CrossRef] [PubMed]

34. van Tilbeurgh, H.; Sarda, L.; Verger, R.; Cambillau, C. Structure of the pancreatic lipase-procolipase complex. Nature 1992, 359, 159-162. [CrossRef] [PubMed]

35. Di Maio, S.; Carrier, R.L. Gastrointestinal contents in fasted state and post-lipid ingestion: In vivo measurements and in vitro models for studying oral drug delivery. J. Control. Release Off. J. Control. Release Soc. 2011, 151, 110-122. [CrossRef] [PubMed]

36. Hofmann, A.F.; Mysels, K.J. Bile acid solubility and precipitation in vitro and in vivo: The role of conjugation, pH, and Ca2+ ions. J. Lipid Res. 1992, 33, 617-626. [PubMed]

37. Lindahl, A.; Ungell, A.L.; Knutson, L.; Lennernas, H. Characterization of fluids from the stomach and proximal jejunum in men and women. Pharm. Res. 1997, 14, 497-502. [CrossRef] [PubMed]

38. Sek, L.P.C.; Kaukonen, A.M.; Charman, W.N. Evaluation of the in-vitro digestion profiles of long and medium chain glycerides and the phase behaviour of their lipolytic products. J. Pharm. Pharm. 2002, 54, 29-41. [CrossRef]

39. Kaukonen, A.M.; Boyd, B.J.; Porter, C.J.; Charman, W.N. Drug solubilization behavior during in vitro digestion of simple triglyceride lipid solution formulations. Pharm. Res. 2004, 21, 245-253. [CrossRef]

40. Kaukonen, A.M.; Boyd, B.J.; Charman, W.N.; Porter, C.J. Drug solubilization behavior during in vitro digestion of suspension formulations of poorly water-soluble drugs in triglyceride lipids. Pharm. Res. 2004, 21, 254-260. [CrossRef]

41. Porter, C.J.H.; Kaukonen, A.M.; Boyd, B.J.; Edwards, G.A.; Charman, W.N. Susceptibility to lipase-mediated digestion reduces the oral bioavailability of danazol after administration as a medium-chain lipid-based microemulsion formulation. Pharm. Res. 2004, 21, 1405-1412. [CrossRef]

42. Porter, C.J.H.; Kaukonen, A.M.; Taillardat-Bertschinger, A.; Boyd, B.J.; O'Connor, J.M.; Edwards, G.A.; Charman, W.N. Use of in vitro lipid digestion data to explain the in vivo performance of triglyceride-based oral lipid formulations of poorly water-soluble drugs: Studies with halofantrine. J. Pharm. Sci. 2004, 93, 1110-1121. [CrossRef] [PubMed]

43. Burgstaller, W. Transport of small lons and molecules through the plasma membrane of filamentous fungi. Crit. Rev. Microbiol. 1997, 23, 1-46. [CrossRef] [PubMed]

(c) 2019 by the authors. Licensee MDPI, Basel, Switzerland. This article is an open access article distributed under the terms and conditions of the Creative Commons Attribution (CC BY) license (http://creativecommons.org/licenses/by/4.0/). 